\title{
Self-perceived Problems in Sleeping and in Self-control Are Related to First Year Study Success in Higher Education
}

\author{
Marije Nije Bijvank ${ }^{1 *}$, Geertje H. Tonnaer ${ }^{2}$ and Jelle Jolles ${ }^{3}$ \\ ${ }^{1}$ Saxion University of Applied Sciences, Study Success Centre, Deventer, Netherlands, ${ }^{2}$ Hospitality Business School, \\ Saxion University of Applied Sciences, Deventer, Netherlands, ${ }^{3}$ Faculty of Behavioral and Movement Sciences, \\ VU University Amsterdam, Centre for Brain and Learning, Amsterdam, Netherlands
}

\section{OPEN ACCESS}

Edited by: Purificación Checa,

University of Cádiz, Spain

Reviewed by: Amedeo D'Angiulli, Carleton University, Canada Raquel Artuch Garde, Universidad Internacional

De La Rioja, Spain Carbonero Martín Miguel Angel, University of Valladolid, Spain

*Correspondence:

Marije Nije Bijvank m.nijebijvank@saxion.nl

Specialty section: This article was submitted to Educational Psychology, a section of the journal Frontiers in Education

Received: 01 February 2017 Accepted: 19 April 2017

Published: 17 May 2017

Citation: Nije Bijvank M, Tonnaer GH and Jolles J (2017) Self-perceived Problems in

Sleeping and in Self-control Are Related to First Year Study Success in Higher Education.

Front. Educ. 2:14. doi: 10.3389/feduc.2017.00014
Late adolescents and emerging adults often report lower sleep quality. Recent studies have shown that many of these individuals are also characterized by ongoing development of executive functions (EFs), such as self-control and self-monitoring (SCSM). These functions are not fully mature until later in the 20s. As both suboptimal sleep and improper EFs can impact academic performance, there could be a relationship between these processes. However, few studies have examined these relationships simultaneously to more fully understand the effects of sleep on academic performance in higher education. The aim of the present study was, therefore, to investigate the extent to which sleep quality influences study success in higher education, and to what extent self-perceived EF influences this possible relationship. A large survey was conducted among 1,760 first-year students at a University of Applied Sciences to evaluate this aim. Results showed that sleep quality and study success are related: lower self-reported sleep quality is related to less study success. A high level of SCSM appears to compensate for the negative effect, which sleeping problems have on obtaining study credits. The results of this large-scale study emphasize the need to include sleep and skills in self-control when planning educational innovations aimed at fostering study success in higher education.

Keywords: adolescence, sleep, self-perceived executive functioning, study success, higher education

\section{INTRODUCTION}

Many adolescents experience changes in their sleep behavior. This is primarily due to a shift in the brain processes, which regulate sleep and the circadian rhythm (Dahl, 2004; Crowly et al., 2007; Galvan et al., 2012). Young adolescents go to bed later than they did in childhood, and many adolescents turn into evening chronotypes (Carskadon et al., 2004). An additional change in sleep pattern occurs over the long period of adolescence. Indications exist that the number of hours spent in bed decreases with age, while restorative demands remain the same, leading many middle and late adolescents to experience lower sleep quality (Maslowsky and Ozer, 2014; Spilsbury et al., 2015). Generally, this tendency is strengthened because the majority of adolescents are confronted with early rising times due to the early start of their lessons at school. Students also have more academic obligations, and they need to spend increasingly more time on homework. Late adolescents can be 
further compromised in sleep quality and consequent daytime functioning, because this group shows an increase in alcohol consumption and in major sleep-related changes in brain physiology (Chan et al., 2015). Likewise, use of electronic devices is frequent in adolescence, both during the day and at bedtime. It has recently been shown that there is a negative correlation between use of technology and sleep (Hysing et al., 2015), with a consequent impact on daily functioning. Therefore, many adolescents build up a form of sleep deprivation during the week (Carskadon et al., 2004; Crowly et al., 2007; Boschloo, 2012; Sivertsen et al., 2014).

Previous studies have provided evidence that changes in sleep behavior can negatively affect school performance. Several authors showed that less sleep, daytime sleepiness, and sleep problems are all related to lower school achievements (e.g., Meijer et al., 2000; Wolfson and Carskadon, 2003; Anderson et al., 2009; Dewald et al., 2010; Perkinson-Gloor et al., 2013). Likewise, lowered awareness and reduced performance on neuropsychological tests have been reported in fatigued individuals (Dahl, 1996; Jones and Harrison, 2001). In one study, sleep problems, defined as the inability to initiate and maintain sleep, are shown to be associated with poor self-regulation (Turnbull et al., 2013), and in another study, a delayed sleep schedule was related to low self-control, to the habit of postponing tasks, and to poor time management (Digdon and Howell, 2008). Anderson et al. (2009) showed that sleep deprivation and sleepiness are associated with decreased performance on neuropsychological tasks, notably in the domain of the executive functions (EFs), which are needed for behavioral planning and control of ongoing activities. Adolescents (aged between 13 and 16 years) with a high score on the Epworth Sleepiness Scale (Anderson et al., 2009) obtained lower scores on two measures of executive functioning. Other research has also suggested that sleep-restricted adolescents require more neural activation to maintain accurate performance on a working memory task compared to well-rested peers (Beebe et al., 2009).

It is well established that sleep quality is related to school performance in secondary school. Given the fact that, by far, the majority of first year students in higher education are late adolescents (aged 17-20 years), it is conceivable that sleep behavior is related to study success in higher education just as has been found in secondary school. However, little research has been done on this relationship in adolescents in the context of higher education. This notion has motivated the current survey study.

The next paragraph describes the potential relationship between adolescents' sleep quality and academic performance in higher education, in terms of possible mechanisms and underlying processes related to neuropsychological performance, notably, executive functioning. The specific focus of this study will then be given.

Adolescents are particularly vulnerable to the effects of suboptimal sleep as elaborated above (Chan et al., 2015; Hysing et al., 2015; Short et al., 2011). This is because various brain areas and networks are still maturing during adolescence and emerging adulthood (up until the age of 25; Giedd, 2008; Giedd and Rapoport, 2010; Steinberg, 2014). Elaborate connections between smaller areas within the brain, as well as systems of microcircuits, develop as the brain matures. Areas in the frontal parts of the brain have an important role in this maturation process (Giedd,
2008; Best et al., 2011; Turnbull et al., 2013). These brain regions and their connections are responsible for cognitive abilities, which are needed to control, plan, and regulate thoughts and behavior (Zimmerman, 2000; Blakemore and Frith, 2005; Amodio and Frith, 2006; Diamond, 2013). More specifically, these abilities, such as the regulation of attention, planning, and self-control, otherwise described as "EFs," are important for academic performance (Zimmerman, 2000, 2001; Shaw et al., 2008; Beauchamp and Anderson, 2010; Giedd and Rapoport, 2010; Diamond, 2013). In the past decade, numerous studies have shown that even late adolescents (aged 17 years and over) are characterized by ongoing development of their EFs (e.g., Veroude et al., 2012, 2013; Crone and Dahl, 2012; Plukaard et al., 2015). Additionally, a recent study showed that students who perceived their EFs to be quite well developed at the start of the first year (aged 17 years and over) of their studies obtained more study credits at the end of that year than students with a lower EF self-rating (Baars et al., 2015).

Late adolescence and emerging adulthood is an important period during which major transitions take place. The transition from secondary education to higher education is often filled with excitement and high expectations, and sometimes even anxious distress in the context of environmental change (Lowe and Cook, 2003; Steinberg, 2014). For example, the structure that students were used to in their home environment is no longer apparent, since the majority of students live on their own. Furthermore, aspects of the new academic learning environment of higher education, such as more independence, require the student to be skilled in monitoring his own intentions and behavior against situational demands. This necessitates mature self-regulation skills in daily life and in the organization of the learning process by the young student. Furthermore, it has been shown that, in adolescence, applying EFs is particularly difficult in an emotional context (Casey et al., 2011) such as during the transition to higher education. This applies also to the situation with which many students are faced, namely the necessity of coping with their newfound freedom and finding their way in a student society, which is characterized by rapidly changing social relationships and friendships.

In the light of the challenges that young students face in their study and life situations, it is highly probable that a lack of sleep may affect the conditions, which are needed for the development of the skills required to adapt to a changing environment-the EFs. As mentioned, these skills are still developing throughout this period of time (Gogtay et al., 2004; Blakemore and Choudhury, 2006; Giedd, 2008; Veroude et al., 2012, 2013). This places the young student at greater risk of lower study success than would be expected based on intelligence and study performance in secondary school. Accordingly, the combination of the ongoing maturation of neuropsychological skills and sleeping problems due to the reported changes poses a challenge to students in this phase of adolescence up until early adulthood (e.g., Steinberg, 2014). These challenges are especially apparent during the first year of higher education.

Being successful in the first year in higher education is a strong indicator for study success throughout the entire period of study (Lowe and Cook, 2003). Indicators for a lack of study success, such as dropping out and study delay, have many short-term and 
long-term negative consequences. This applies to both students and universities and is thus a major problem for many higher education institutions. For example, in the Netherlands, 51\% of first-year students at universities of applied sciences do not graduate within 5 years of starting their 4 -year study program. Furthermore, on average, almost $16 \%$ of all students drop out of higher education completely within their first year, and $20 \%$ of students change to another course or educational institution (Vereniging Hogescholen, 2016). These alarming figures are additional reasons to study the possible determinants of this lack of study progress and high dropout rate.

As mentioned above, previous studies have investigated sleep, school performance, and particular neuropsychological tests, including EF. The majority of these studies focused upon either sleep or executive functioning, and there is a need to examine these relationships simultaneously to more fully understand the effects of sleep on daytime functioning (e.g., Short et al., 2013) and more specifically on academic performance in higher education. There is only one study, which investigated the combined influence of (subjective) sleep quality and level of EF on school performance as measured by tests of language and mathematics. In this study (Boschloo, 2012), participants were students in secondary education in the age range of 14-15 years. Results showed that those early adolescents who had the better sleep quality also reported better self-perceived executive functioning. Early adolescents with better self-perceived executive functioning had better performance on language tests. For sleepiness, no direct effect on school performance was found (Boschloo, 2012).

In the present study, the aim was to investigate to what extent sleep quality influences study success in higher education, and to what extent self-perceived executive functioning influence this possible relationship. A large survey study was conducted among 1,760 first-year students from Saxion University of Applied Sciences. Respondents were questioned on various aspects of their neuropsychological and biopsychological functioning, and their ratings were combined with objective study progress data. The hypothesis was that self-reported quality of sleep is related to study success, with a higher reported sleep quality resulting in greater study success. Furthermore, given the insights into the development of executive functioning mentioned above, it was expected that the level of self-perceived EF influences the relationship between sleep and first-year study success.

Adolescent sleep research is usually focused on sleep duration. However, other aspects of sleep, such as sleep quality, are increasingly recognized as affecting adolescent well-being and functioning. This appears to be important for learning and cognitive performance (Short et al., 2013). The present study evaluates student's self-reported quality of sleep. Three aspects of self-perceived EF were measured by means of self-reporting using a validated questionnaire (Van der Elst et al., 2012). Such a selfreport questionnaire was preferred over the use of tests, and is more suitable for this study, because of the interest in self-insight and behavior (and not on cognitive performance, for which EF tests are more suitable). Note that also the widely used Behavioral Rating Inventory of Executive Functioning (Gioia et al., 2000) investigates the self-evaluation of various aspects of executive functioning and has been used in many studies and (thousands of) scientific papers. Self-report questionnaires are the method of choice for the assessment of subjective functioning (Gioia and Isquith, 2004; Guy et al., 2004; Van der Elst et al., 2012; Teterink and Jolles, 2017).

\section{MATERIALS AND METHODS}

\section{Procedure and Participants}

Data collection for this study was part of a large survey conducted among first-year students at Saxion University of Applied Sciences in the Netherlands. Saxion UAS is a regular Dutch university of applied sciences. The self-reported data on demographics, study behavior, executive functioning, and lifestyle were measured at the start of students' first academic year. The in-classroom survey was performed by asking students to voluntarily participate in filling out a questionnaire. The students were informed that no personalized data would be used in the analyses and that no personalized results would be obtained, since all data are assembled on group level. A personal code was only used to link questionnaire data with the administrative study progress database. The teachers were instructed to hand out the forms and gather them back in after students had time to fill them in (approximately 20 min per questionnaire). Furthermore, for this questionnaire, the option was provided to stay anonymous, and only a very limited number of students are, therefore, not included in our study (since it was not possible to combine their questionnaire results with data on study progress). In addition to that, we progressed and analyzed the data to conform to all ethical rules, and the questionnaire was performed in accordance with the approval of the Ethical Committee.

The questionnaire data were combined with objective data on study progress retrieved from the student registry at the end of students' first academic year. This linkage was done in compliance with the ethical guidelines set up by the university. These guidelines entail that one person is responsible for the linkage of data and ensures that the resulting new database has been made anonymous. It is not possible to trace information back to individual students in this database.

About 1,760 first year students who started their studies between 2010 and 2013 were included in the study. The sample distribution for gender was comparable with the population. The sample represents $30.8 \%$ males and $69.2 \%$ females, and the population distribution shows $33.5 \%$ males and $66.4 \%$ females. The students' mean age was 19.3 years and the range was $16-25$ years. Most students enrolled in the study came from senior general secondary education (49.6\%), followed by secondary vocational education (24.1\%), and university preparatory education (11.4\%). $14.9 \%$ of the respondents came from higher vocational education at another institution.

\section{Measurements}

\section{Sleep Quality}

Sleep quality encompasses two broad aspects of sleep: the ability to initiate and maintain sleep, and a subjective feeling of rejuvenation or refreshment following sleep (Akersted et al., 1994). Therefore, the level of self-reported sleep quality was measured by two constructs: sleeping problems and daytime sleepiness. These 
measurements are in line with previous studies (Boschloo et al., 2013), where problems experienced regarding these two aspects were most prevalent. In addition, since this survey included a large number of participants, and the measurements were part of a larger survey, we chose to use this compact measure of sleep variables. Sleeping problems $(\alpha=0.72)$ were measured with a mean score based on three questions, which refer to distinct processes affecting sleep quality: (1) I regularly have trouble falling asleep; (2) I often wake up at night and have trouble falling asleep again; (3) I often wake up early and have trouble falling asleep again. Daytime sleepiness $(\alpha=0.59 / r=0.42)$ was measured by putting the following propositions to the adolescents: (1) I feel sleepy during the first hours at school; (2) I have trouble waking up in the morning, and when the alarm clock rings, I have trouble getting up. The mean of both items is included in these analyses. Answers were given on a five-point Likert scale ranging from "totally agree" (five points) to "totally disagree" (one point).

\section{Self-perceived Executive Functioning}

Executive functioning involves many interconnected functions and abilities. The validated rating scale Amsterdam executive function inventory (AEFI) was developed to measure only three aspects of subjective executive functioning; these have also been described in many earlier papers (Gioia et al., 2000; Van der Elst et al., 2012; Diamond, 2013). The AEFI is particular suitable for the measurement of subjective executive functioning in middle and late adolescents at school by means of a short self-report questionnaire. Answers were given on a five-point Likert scale ranging from "totally agree" (five points) to "totally disagree" (one point). Validity and reliability were evaluated in a large sample of adolescents aged 15-18 years (Van der Elst et al., 2012). In another study, some adjustments were made to the wording of the questions in order to suit the current group of respondents (Baars et al., 2015). Furthermore, the list was reduced from 13 to 10 items in the adjusted version. The adapted version of the AEFI focuses on the level of self-perceived attention, planning, and on self-control and self-monitoring (SCSM) (Baars et al., 2015).

\section{Study Success}

Two objective measures of study success were used in this study. The first was dropout during the first year ("yes/no"). The second was the total number of study credits according to the European Credit Transfer and Accumulation System (ECTS EU, 2015), achieved on first exam attempts during the first year of higher education. The maximum amount of ECTS that could be attained in year one was 60 .

\section{Background Factors}

Level of previous education and gender were measured to control the potential influence of these background factors. Previous education consisted of three levels and was, therefore, included as a dummy variable where the intermediate vocational education was used as the reference category, higher general secondary education as "PE dum 1," and pre-university education as "PE dum 2."

\section{Analyses}

Logistic regression was performed to analyze the relationship between sleep quality (sleeping problems and daytime sleepiness) and three factors from the domain of self-perceived executive functioning (attention, planning, and SCSM) on dropout. Linear regression analyses were used to test for associations between sleep quality and amount of study credits. Analyses of interactions between self-reported sleep quality and three self-perceived EFs were performed using regression analyses as well. All statistical analyses were performed using IBM SPSS Statistics for Windows, Version 22.0.

\section{RESULTS}

\section{Descriptive Statistics}

Results of factor and reliability analyses show that the three EF measurement scales of the adapted AEFI are reliable (Table 1). In Table 2, the distribution of the background characteristics included in the present study is presented. Table $\mathbf{3}$ shows the descriptive values of the variables of interest. All scales measured with Likert-type items were treated as interval variables in the analyses (Norman, 2010).

Attention appears to be least developed as the average score is the lowest. Second, sleeping problems are less apparent than daytime sleepiness. Roughly, $17 \%$ of the students experience moderate-to-severe sleeping problems, and almost 60\% experience moderate or severe sleepiness throughout the day.

TABLE 1 | Factor and reliability analyses for the adapted Amsterdam executive function inventory (AEFI).

\begin{tabular}{lcc}
\hline Variable & $\begin{array}{c}\text { Factor loadings } \\
\text { adapted AEFI }\end{array}$ & Cronbach's $\boldsymbol{\alpha}$-adapted AEFI \\
\hline Attention & 0.81 & 0.78 \\
Planning & 0.74 & 0.65 \\
Self-control and & 0.71 & 0.69 \\
self-monitoring & & \\
\hline
\end{tabular}

TABLE 2 | Distribution of gender and level of education.

\begin{tabular}{lcc}
\hline & N & Valid (\%) \\
\hline Gender & 539 & \\
Male & 1,211 & 30.8 \\
Female & & 69.2 \\
Level of education & 420 & \\
Intermediate vocational education & 863 & 24.1 \\
Higher general secondary education & 199 & 49.6 \\
Pre-university secondary education & 259 & 11.4 \\
Higher education other & & 14.9 \\
\hline
\end{tabular}

TABLE 3 | Distribution of self-perceived executive functions (EFs) and sleep quality.

\begin{tabular}{lccccc}
\hline & N & Min & Max & Mean & SD \\
\hline EF-attention & 1,752 & 1 & 5 & 2.85 & 0.72 \\
EF-SCSM & 1,754 & 1.25 & 5 & 3.46 & 0.61 \\
EF-planning & 1,754 & 1 & 5 & 3.49 & 0.68 \\
Sleeping problems & 1,754 & 1 & 5 & 2.11 & 0.79 \\
Daytime sleepiness & 1,753 & 1 & 5 & 3.01 & 0.92 \\
Study credit & 1,474 & 0 & 60 & 40.89 & 17.18 \\
Dropout (in \%) & 1,760 & 0 & 1 & $19 \%$ &
\end{tabular}




\section{Influence on Dropout Rates}

Table 4 presents results of the logistic regression analyses on the effect of sleeping problems on dropout, in combination with the three self-perceived EFs.

Results show that males have a higher risk than females of dropping out in the first year of higher education $[\operatorname{Exp}(B)=1.368]$. Furthermore, a higher level of previous education reduces the risk of dropping out in the first year. Self-perceived planning also influenced dropout. Higher scores on self-reported planning were correlated to lower risk of dropping out $[\operatorname{Exp}(B)=0.698]$. Attention and SCSM showed no effect on dropout rates. Finally, students experiencing more sleeping problems at the beginning of the first year were characterized by a higher risk of dropping out $[\operatorname{Exp}(B)=1.222]$.

The interaction of the three self-perceived EFs with sleeping problems were added, and the effects of these interaction factors on dropout appeared not to be significant.

\section{Influence on Study Credits}

The influence of sleep quality and the self-perceived EFs was also analyzed for the effect on the dependent variable study credits, the second measurement of study success. These findings are presented in Table 5.

Table 5 shows the results of several separate regression analyses, and the values of the final model that combined all variables. The reported adjusted $R^{2}$ indicate the explained variance of each

TABLE 4 | Results of logistic regression model of self-perceived executive functions in association to background characteristics and sleeping problems with dropout.

\begin{tabular}{lcrcrrr}
\hline Variable & $\operatorname{Exp}(\boldsymbol{B})_{\text {base }}$ & & $\operatorname{Exp}(\boldsymbol{B})_{\text {sleep }}$ & & \multicolumn{3}{c}{$\operatorname{Exp}(\boldsymbol{B})_{\text {all }}$} & \\
\hline Constant & 0.518 & $*$ & 0.096 & $* *$ & 0.416 & - \\
Sex & 1.410 & $* *$ & 1.540 & $* *$ & 1.368 & $*$ \\
PE dum 1 & 0.678 & $*$ & 0.697 & $*$ & 0.684 & $*$ \\
PE dum 2 & 0.586 & $*$ & 0.617 & $*$ & 0.646 & $*$ \\
Sleeping problems & & & 1.267 & $*$ & 1.222 & $* *$ \\
Planning & & & & & 0.698 & $* *$ \\
Nagelkerke R-square & 0.025 & & 0.034 & & 0.047 & \\
\hline
\end{tabular}

$N=1,750,{ }^{* *} p<0.01,{ }^{*} p<0.05,-p<0.10$.

TABLE 5 | Results of separate linear regression analyses of self-perceived executive functions in association to background characteristics and sleeping problems with obtained study credits.

\begin{tabular}{|c|c|c|c|c|c|c|c|c|}
\hline Variable & $b_{\text {base }}$ & & $\boldsymbol{b}_{\text {sleep }}$ & & $\boldsymbol{b}_{\text {total }}$ & & $\boldsymbol{b}_{\text {interact }}$ & \\
\hline Intercept & 26.595 & $* *$ & 51.025 & $* *$ & 31.055 & $* *$ & 46.596 & $* *$ \\
\hline Sex & -6.723 & $* *$ & -7.068 & $* *$ & -5.946 & $* *$ & -6.005 & $* *$ \\
\hline PE dum 1 & 4.786 & $* *$ & 4.670 & $* *$ & 4.754 & $* *$ & 4.725 & $* *$ \\
\hline PE dum 2 & 9.420 & $* *$ & 9.123 & $* *$ & 9.107 & $* *$ & 9.015 & $* *$ \\
\hline Sleeping problems & & & -2.127 & $* *$ & -1.616 & $* *$ & -8.981 & $* *$ \\
\hline Planning & & & & & 3.210 & $* *$ & 3.159 & n.s. \\
\hline $\begin{array}{l}\text { Self-control and } \\
\text { self-monitoring }\end{array}$ & & & & & 1.802 & $*$ & -2.663 & $* *$ \\
\hline $\begin{array}{l}\text { Sleeping } \\
\text { problems } \times \text { self- } \\
\text { control self-monitoring }\end{array}$ & & & & & & & 2.170 & $*$ \\
\hline Adjusted $R$-square & 0.061 & & 0.070 & & 0.090 & & 0.094 & \\
\hline
\end{tabular}

$N=1,464,{ }^{* *} p<0.01,{ }^{*} p<0.05$, n.s., not significant. regression model. The increases in the reported adjusted $R^{2}$ were significant $(p<0.01)$. Results show that a higher level of previous education leads to a higher amount of obtained study credits at the end of the first year. Males appear to have a lower amount of study credits at the end of the year than female students $\left(b=-6.723^{\star \star}\right)$. Results also show that more sleeping problems $\left(b=-2.127^{\star *}\right)$ reported at the beginning of the year is related to obtaining fewer study credits at the end of the first year. Furthermore, higher scores on self-reported planning $\left(b=3.210^{\star *}\right)$ and self-control and self-regulation $(\mathrm{SCSM})\left(b=1.802^{*}\right)$ show more obtained study credits.

The interaction of SCSM with sleeping problems appeared to significantly affect obtained study credits $\left(b=2.170^{*}\right)$. More specifically, the effect of sleeping problems on study credits is only apparent when SCSM is low. High SCSM seems to compensate for the effect of experiencing sleeping problems on obtained study credits. The interaction of planning with sleeping problems, and attention with sleeping problems on obtained study credits were not significant.

The same analyses were conducted for the effect of daytime sleepiness on dropout rates, and study credits, combined with EF. The findings indicate that the effect of daytime sleepiness with EFs on dropout and study credits was not significant.

\section{CONCLUSION}

Results confirm the hypothesis that self-reported quality of sleep plays a significant role in study success. It appeared that students with a higher sleep quality had more study success in their first year in higher education. Sleeping problems have a negative influence on achieved study credits and reduce the risk of dropping out. These results are also in line with previous studies on the impact of sleep quality on academic performance in secondary school (Wolfson and Carskadon, 2003; Dewald et al., 2010; PerkinsonGloor et al., 2013). Furthermore, results of this study add to this body of knowledge by proving that SCSM influence the relationship between sleep and first-year study success. Interestingly, in this study, the effect of sleeping problems on study credits only affects students with low SCSM. High scores on SCSM seem to be able to neutralize the effect of low sleep quality on obtained study credits. The findings are selective in that this effect was not found for daytime sleepiness.

\section{DISCUSSION}

There have been only a limited number of studies into the combined effect of self-control and sleep on study success in higher education among late adolescents. Therefore, the results of this study provide a contribution to the research domain of individual differences in first year study success within the context of higher education. Although study success is dependent upon many factors that have been widely investigated, the present study provides a new focus, which can have an impact on study performance, and possibly also on educational interventions targeted at improving study performance. More specifically, this study focusses on biopsychological factors that are responsible for individual differences between adolescents. Biopsychological factors may be 
more important than hitherto recognized, and the findings of this study highlight the importance of sleep quality. This factor should be included in the broad discussion that is present in many industrialized countries about how we could support students in being successful throughout their first year in higher education.

This is particularly true for the relationship with SCSM. The mechanism through which these important EFs and sleep exert their influence on learning performance in higher education is probably related to cognitive fatigue (Plukaard et al., 2015), since insufficient self-control in the student requires cognitive effort. More cognitive effort and "controlled processing" are needed when the student is fatigued because of prolonged suboptimal sleep. This costs time and effort, which might lead to a vicious circle, and thereby a lower study performance than is possible given the intelligence of the student (Plukaard et al., 2015). Thus, especially when the major neuropsychological skills, which fall under the umbrella of the EF are underdeveloped, low sleep quality is a significant risk factor for poor academic performance. The observed negative influence of sleeping problems on study success, in combination with low SCSM as an aspect of self-perceived EF, indicate that some students are more than capable of facing the challenges in higher education and being successful, while others need more support and guidance to make it through the first year and beyond. This might explain why there are individual differences in study performance that have to do with the proficiency in skills on the broad domain of executive functioning, as also found in the study on students in higher education by Baars et al. (2015).

Although sleeping problems appeared to be related to study success and self-perceived EFs, the combined effect of experienced sleepiness with SCSM was unrelated to study success. Some previous studies do show a relationship between sleepiness and school performance (Dewald et al., 2010) and some studies do not (Boschloo, 2012). At the same time, the majority of adolescents do experience sleepiness in the morning (Crowly et al., 2007). This was also true in the present study; the majority of students in this study, both high and low achieving in terms of study performance, experience sleepiness. It is of interest that the majority of the subjects in this study experience sleepiness. This may be related to the activity pattern of many students in higher education, which is often characterized by disrupted sleep-wake cycles and irregular living patterns, but also by incidental periods of prolonged stress during times that the student has to work on assignments. On the other hand, sleeping problems can be the consequence of more cognitive aspects, like improper planning and regulation of study activities (e.g., "I have to complete 100 study hours in the next week...") and emotional problems, which the student encounters when realizing that their study regulation is not as it should be ("I am afraid that I won't pass this test and that could impact my whole year"). So it could be that sleepiness per se is not the relevant factor, since it is more related to lifestyle and rhythm, while sleeping problems are founded on the mechanism of cognitive work and thinking. We hypothesize that all these processes are important, with a major role for self-monitoring and self-control, such as study-planning, selfregulation, and resistance against distraction by the peer group. The relatively unskilled student spends more effort in planning and executing his study and personal life. And such an effort can lead to cognitive tiredness and lower performance as discussed above. The present findings are relevant also for applied purposes, and they demand more research to deepen our understanding of the underlying process of sleepiness in relation to life and study planning with its impact on study performance.

Higher education institutions should educate both employees and students on the importance of sleep- and EF-related processes such as SCSM, which were investigated in the present paper. The findings suggest that the student should be educated in developing skills within the domain of SCSM. This may make the student better equipped to self-regulate their studies. This educational need has further implications not only for teachers but also for student-counseling facilities and policies. For example, early signaling of sleep problems and skills in the domain of EF will lead to early identification of students who are vulnerable to a delay in study progress and who are at risk of dropping out. Identification of vulnerable students enables institutions to tackle these issues at an early stage of their studies, and institutions could provide tailored support. Training these adolescents in self-control could be a relevant procedure in this respect and could for example focus on learning to resist distraction, to prioritize, and to make timely judgments in terms of what is needed in their study. Institutions should also create awareness of the effects that sleep might have on study success, and provide tools to foster students' own literacy and to support self-help in both sleeping problems, and SCSM. Cognitive fatigue may also be an important factor to consider, especially given the fact that fatigue develops when self-regulation and planning behavior, as well as cognitive flexibility-i.e., important EFs-are compromised (Plukaard et al., 2015).

This is the first study into the combined effect of self-perceived EFs and sleep on study success, and the interaction effect that was found adds to the current body of knowledge. Follow-up research should be directed at the validation of these findings and could provide a better understanding of the relation between sleep quality and study success, and the role of SCSM.

The current study has several issues worthy of discussion regarding the meaning and implications of the results. Although deliberately chosen, the design does not allow conclusions to be drawn about the development of the variables and their relations in this study. Longitudinal studies into these effects would lead to insight into the development of SCSM, and other EFs and sleep quality, and the relationship they have with study success. A strength of this study is that self-reported EFs and sleep quality (as measured at the beginning of the first year) were related to study progress data at a later stage (after the first year) and, herewith, the findings indicate the potential.

Our choice to use self-reported questionnaires enabled us to study the subjective experience of students. Questionnaires have an advantage in this respect above neuropsychological tests and biopsychological measures. These instruments can be used for the measurement of objective cognitive functioning, but they are not appropriate for the evaluation of self-insight and other self-perceived functions and sleep. Questionnaires and other self-report measures can, therefore, be used to measure daily life functioning as perceived by the subject. With respect to the sleep quality that was measured subjectively in the present study, it is possible that students over- or underestimate their sleep quality. 
This could affect the outcomes and, therefore, more research is needed to provide more insight into the biopsychological processes involved. In addition, more research is needed into the background of the subjective sleeping problems that were found in this study. Are they possibly related to the fact that late adolescents are not yet very skilled in planning or prioritizing? Does it have to do with stress related to their studies or with daily hassles that are difficult to cope with? Follow-up studies should be performed into these possibilities, as an answer may provide the means to find students at risk, and to design specific interventions.

With respect to the finding that the explained variance of each presented model is relatively low, it should be pointed out that the models are significant and appear to confirm the relationships studied. Although the findings are not conclusive, they provide enough grounds to elaborate on the findings in future research that is needed to look for a more explicative model. It is also of importance to perform follow-up studies into the question of causation. Improper SCSM could be the cause of frequent sleeping problems, but it could also be the other way around: sleeping problems can lead to decreases in neuropsychological functioning. It is of interest in that respect to plan and execute training studies in which students are trained in SCSM and related EFs. It is our hypothesis that such training can improve academic performance by providing the student with major neuropsychological skills in the domain of EF.

\section{REFERENCES}

Akersted, T., Hume, K., Minors, D., and Waterhouse, J. (1994). The meaning of good sleep: a longitudinal study of polysomnography and subjective sleep quality. J. Sleep Res. 3, 152-158. doi:10.1111/j.1365-2869.1994.tb00122.x

Amodio, D. M., and Frith, C. D. (2006). Meeting of minds: the medial frontal cortex and social cognition. Nat. Rev. Neurosci. 7, 268-277. doi:10.1038/nrn1884

Anderson, B., Storfer-Isser, A., Taylor, H. G., Rosen, C. L., and Redline, S. (2009). Associations of executive function with sleepiness and sleep duration in adolescents. Pediatrics 123, 701-707. doi:10.1542/peds.2008-1182

Baars, L., Nije Bijvank, M., Tonnaer, G., and Jolles, J. (2015). Self-report measures of executive functioning are a determinant of academic performance in first-year students at a university of applied sciences. Front. Psychol. 6:1131. doi:10.3389/ fpsyg.2015.01131

Beauchamp, M. H., and Anderson, V. (2010). SOCIAL: an integrative framework for the development of social skills. Psychol. Bull. 136, 39-64. doi:10.1037/ a0017768

Beebe, D., Difrancesco, M., Tlustos, S., McNally, K., and Holland, S. (2009). Preliminary fMRI findings in experimentally sleep restricted adolescents engaged in a working memory task. Behav. Brain Funct. 5, 9-14. doi:10.1186/ 1744-9081-5-9

Best, J. R., Miller, P. H., and Naglieri, J. A. (2011). Relations between executive function and academic achievement from ages 5 to 17 in a large, representative national sample. Learn. Individ. Differ. 21, 327-336. doi:10.1016/j.lindif. 2011.01.007

Blakemore, S. J., and Choudhury, S. (2006). Development of the adolescent brain: implications for executive function and social cognition. J. Child Psychol. Psychiatry 47, 296-312. doi:10.1111/j.1469-7610.2006.01611.x

Blakemore, S. J., and Frith, U. (2005). The Learning Brain: Lessons for Education. Oxford, UK: Blackwell Publishing.

Boschloo, A. M. (2012). School Performance in Adolescents: An Educational Europsychology Perspective. Ridderkerk: Ridderprint.

Boschloo, A. M., Krabbendam, L., Dekker, S., Lee, N., de Groot, R., and Jolles, J. (2013). Subjective sleepiness and sleep quality in adolescents are related to objective and subjective measures of school performance. Front. Psychol. 4:38. doi:10.3389/fpsyg.2013.00038
The present investigation and its possible follow-up may advance our understanding of the challenges that many students face. It might provide us with means and measures to prevent students from potential delays in their study progress and even help prevent them from dropping out. This may help them in achieving study success in higher education, which as such is of importance for both the individual student and for the educational organization.

\section{ETHICS STATEMENT}

The study was performed under the ethical guidelines of Free University Amsterdam and the LEARN research institute. With respect to approval by a Medical Ethical Committee, the project falls under the umbrella of large-scale research program into study performance and its determinants in students in the higher education domain, for which approval has been obtained.

\section{AUTHOR CONTRIBUTIONS}

The main sections of the article have been written by MNB. Methodology and results have been written by both GT and $\mathrm{MNB}$, and the basis for the theoretical background is provided by JJ. The discussion is written by MNB, JJ and GT, and overall editing has been done by MNB and JJ.

Carskadon, M. A., Acebo, C., and Jenni, O. G. (2004). Regulation of adolescent sleep. Implications for behavior. Ann. N. Y. Acad. Sci. 1021, 276-291. doi:10.1196/ annals.1308.032

Casey, B., Jones, R. M., and Somerville, L. H. (2011). Braking and accelerating of the adolescent brain. J. Res. Adolesc. 21, 21-33. doi:10.1111/j.1532-7795. 2010.00712.x

Chan, J. K. M., Trinder, J., Colrain, I. M., and Nicholas, C. L. (2015). The acute effects of alcohol on sleep electroencephalogram power spectra in late adolescence. Alcohol. Clin. Exp. Res. 39, 291-299. doi:10.0000/acer. 12621

Crone, E. A., and Dahl, R. E. (2012). Understanding adolescence as a period of social-affective engagement and goal flexibility. Nat. Rev. Neurosci 13, 636-650. doi: $10.1038 /$ nrn3313

Crowly, S. J., Acebo, C., and Carskadon, M. A. (2007). Sleep, circadian rhythms, and delayed phase in adolescence. Sleep Med. 8, 602-612. doi:10.1016/j. sleep.2006.12.002

Dahl, R. E. (1996). The regulation of sleep and arousal: development and psychopathology. Dev. Psychopathol. 8, 3-27. doi:10.1017/S0954579400006945

Dahl, R. E. (2004). Regulation of sleep and arousal. Comments on part VII. Ann. N. Y. Acad. Sci. 1021, 292-293. doi:10.1196/annals.1308.033

Dewald, J. F., Meijer, A. M., Oort, F. J., Kerkhof, G. A., and Bogels, S. M. (2010). The influence of sleep quality, sleep duration and sleepiness on school performance in children and adolescents: a meta-analytic review. Sleep Med. Rev. 14, 179-189. doi:10.1016/j.smrv.2009.10.004

Diamond, A. (2013). Executive functions. Annu. Rev. Psychol. 64, 135-168. doi:10.1146/annurev-psych-113011-143750

Digdon, N., and Howell, A. (2008). College students who have an eveningness preference report lower self-control and greater procrastination. Chronobiol. Int. 25, 1029-1046. doi:10.1080/07420520802553671

EU. (2015). ECTS Users' Guide. E. Union. Luxembourg: Publications Office of the European Union.

Galvan, A., Van Leijenhort, L., and McGlennen, K. M. (2012). Considerations for imaging the adolescent brain. Dev Cogn Neurosci. 2, 293-302. doi:10.1016/j. dcn.2012.02.002

Giedd, J. N. (2008). The teen brain: insights from neuroimaging. J. Adolesc. Health 42, 335-343. doi:10.1016/j.jadohealth.2008.01.007 
Giedd, J. N., and Rapoport, J. L. (2010). Structural MRI of pediatric brain development: what have we learned and where are we going? Neuron 67, 728-734. doi:10.1016/j.neuron.2010.08.040

Gioia, G. A., and Isquith, P. K. (2004). Ecological Veroude, K., Jolles, J., Croiset, G., and Krabbendam, L. assessment of executive function in traumatic brain injury. Dev. Neuropsychol. 25, 135-158. doi:10.1080/87565641.2004.9651925

Gioia, G. A., Isquith, P. K., Guy, S. C., and Kenworthy, L. (2000). Behavior rating inventory of executive function. Child Neuropsychol. 6, 235-238. doi:10.1076/ chin.6.3.235.3152

Gogtay, N., Giedd, J. N., Lusk, L., Hayashi, K. M., Greenstein, D., Vaituzis, A. C., et al. (2004). Dynamic mapping of human cortical development during childhood through early adulthood. Proc. Natl. Acad. Sci. U. S. A. 101, 8174-8179. doi:10.1073/pnas.0402680101

Guy, S. C., Isquith, P. K., and Gioia, G. A. (2004). Behavior Rating Inventory of Executive Function - Self-Report Version. Lutz, FL: Psychological Assessment Resources.

Hysing, M., Pallesen, S., Stormark, K. M., Jakobsen, R., Lundervold, A. J., and Sivertsen, B. (2015). Sleep and use of electronic devices in adolescence: results from a large population-based study. BJM Open 5:e006748. doi:10.1136/ bmjopen-2014-006748

Jones, K., and Harrison, Y. (2001). Frontal lobe function, sleep loss and fragmented sleep. Sleep Med. Rev. 5, 463-475. doi:10.1053/smrv.2001.0203

Lowe, H., and Cook, A. (2003). Mind the gap: are students prepared for higher education. J. Further High. Educ. 27, 53-76. doi:10.1080/03098770305629

Maslowsky, J., and Ozer, E. J. (2014). Developmental trends in sleep duration in adolescence and young adulthood: evidence from a national united states sample. J. Adolesc. Health 54, 691-697. doi:10.1016/j.jadohealth.2013.10.201

Meijer, A. M., Habekothe, H. T., and Van den Wittenboer, G. L. H. (2000). Time in bed, quality of sleep and school functioning of children. J. Sleep Res. 9, 145-153. doi:10.1046/j.1365-2869.2000.00198

Norman, G. (2010). Likert scales, levels of measurement and the "laws" of statistics. Adv. Health Sci.Educ. Theory Pract. 15, 625-632. doi:10.1007/s10459-010-9222-y

Perkinson-Gloor, N., Lemola, S., and Grob, A. (2013). Sleep duration, positive attitude towards life, and academic achievement: the role of daytime tiredness, behavioural persistence, and school start times. J. Adolesc. 36, 311-318. doi:10.1016/j.adolescence.2012.11.008

Plukaard, S., Huizinga, M., Krabbendam, L., and Jolles, J. (2015). Cognitive flexibility in healthy students is affected by fatigue: an experimental study. Learn. Individ. Differ. 38, 18-25. doi:10.1016/j.indif.2015.01.003

Shaw, P., Kabani, N. J., Lerch, J. P., Eckstrand, K., Lenroot, R., Gogtay, N., et al. (2008). Neurodevelopmental trajectories of the human cerebral cortex. J. Neurosci. 28, 3586-3594. doi:10.1523/JNEUROSCI.5309-07.2008

Short, M. A., Gradisar, M., Lack, L. C., and Wright, H. R. (2013). The impact of sleep on adolescent depressed mood, alertness and academic performance. J. Adolesc. 36, 1025-1033. doi:10.1016/j.adolescence.2013.08.007

Short, M. A., Gradisar, M., Wright, H., Lack, L. C., Dohnt, H., and Carskadon, M. A. (2011). Time for bed: parent-set bedtimes associated with improved sleep and daytime functioning in adolescents. Sleep 34, 797-800. doi:10.5665/SLEEP.1052

Sivertsen, B., Harvey, A. G., Lundervold, A. J., and Hysing, M. (2014). Sleep problems and depression in adolescence: results from a large population-based study of Norwegian adolescents aged 16-18 years. Eur. Child Adolesc. Psychiatry 23, 681-689. doi:10.1007/s00787-013-0502-y

Spilsbury, J. C., Storfer-Isser, A., Rosen, C. L., and Redline, S. (2015). Remission and incidence of obstructive sleep apnea from middle childhood to late adolescence. Sleep 38, 23-29. doi:10.5665/sleep.4318

Steinberg, L. (2014). Age of Opportunity. Lessons from the New Science of Adolescence. Boston, MA; New York, NY: Houghton Mifflin Harcourt.

Teterink, M., and Jolles, J. (2017). Teacher evaluations of executive functioning in schoolchildren aged 9-12 and the influence of age, sex, level of parental education. Front. Psychol. 8:1-10. doi:10.3389/fpsyg.2017.00481

Turnbull, K., Reid, G. J., and Morton, J. B. (2013). Behavioral Sleep problems and their potential impact on developing executive function in children. Sleep 36, 1077-1084. doi:10.5665/sleep. 2814

Van der Elst, W., Ouwehand, C., van der Werf, G., Kuyper, H., Lee, N., and Jolles, J. (2012). The Amsterdam Executive Function Inventory (AEFI): psychometric properties and demographically corrected normative data for adolescents aged between 15 and 18 years. J. Clin. Exp. Neuropsychol. 34, 160-171. doi:10.1080/ 13803395.2011 .625353

Vereniging Hogescholen. (2016). Feiten en Cijfers. Afgestudeerden en uitvallers in het hoger beroepsonderwijs. Available at: www.vereniginghogescholen.nl/ system/knowledge_base/attachments/files/000/000/538/original/Factsheet_ Uitval_en_Rendement_2016_def.pdf?1461314326

Veroude, K., Jolles, J., Croiset, G., and Krabbendam, L. (2013). Sex differences in the neural bases of social appraisals. Soc. Cogn. Affect. Neurosci. 9, 513-519. doi:10.1093/scan/nst015

Veroude, K., Keulers, E. H., Evers, E. A., Stiers, P., Krabbendam, L., and Jolles, J. (2012). The effect of perspective and content on brain activation during mentalizing in young females. J. Clin. Exp. Neuropsychol. 34, 227-234. doi:10.1080/ 13803395.2011.630650

Wolfson, A. R., and Carskadon, M. A. (2003). Understanding adolescents' sleep patterns and school performance: a critical appraisal. Sleep Med. Rev. 7, 491-506. doi:10.1016/S1087-0792(03)90003-7

Zimmerman, B. J. (2000). “Attaining self-regulation: a social cognitive perspective," in Handbook of Self-Regulation, eds M. Boekaerts, P. Pintrich, and M. Zeodmer (San Diego, CA: Academic Press), 13-39.

Zimmerman, B. J. (2001). "Theories of self-regulated learning and academic achievement: an overview and analysis," in Self-Regulated Learning and Academic Achievement: Theoretical Perspectives, eds B. J. Zimmerman and D. H. Schunk (Mahwah, NJ: Lawrence Erlbaum Associates), 1-37.

Conflict of Interest Statement: The authors declare that the research was conducted in the absence of any commercial or financial relationships that could be construed as a potential conflict of interest.

Copyright (c) 2017 Nije Bijvank, Tonnaer and Jolles. This is an open-access article distributed under the terms of the Creative Commons Attribution License (CC BY). The use, distribution or reproduction in other forums is permitted, provided the original author(s) or licensor are credited and that the original publication in this journal is cited, in accordance with accepted academic practice. No use, distribution or reproduction is permitted which does not comply with these terms. 